\title{
Narrative as An Approach in Teacher Preparation Programme
}

\author{
Norzihani Saharuddin ${ }^{1, *}$, Suhailah Hussein ${ }^{2}$, Nur Surayyah Madhubala Abdullah ${ }^{1}$, Maizura Yasin ${ }^{1}$ \\ ${ }^{1}$ Faculty of Educational Studies, Universiti Putra Malaysia. Malaysia \\ ${ }^{2}$ Kuliyyah of Education, International Islamic University Malaysia. Malaysia
}

Received October 27, 2019; Revised December 30, 2019; Accepted January 15, 2020

Copyright $\bigcirc 2020$ by authors, all rights reserved. Authors agree that this article remains permanently open access under the terms of the Creative Commons Attribution License 4.0 International License

\begin{abstract}
This study explored the experience of preservice teachers in a coursework that was instructed using the Narrative Approach in University Putra Malaysia. In doing so, the study intended to examine the perceptions of the preservice teachers about learning in a Narrative Approach classroom. This study is a case study of six preservice teachers in their sixth semester of the Teacher Education Programme in UPM. The main data collection technique was semi-structured interview with the six preservice teachers and triangulation with the researcher's class observation and semi-structured interview with the LHE 3313's (Moral Issues and Conflicts). The data were transcribed, analysed and the emerging themes were categorised and discussed. The findings revealed that the preservice teachers generally had mixed perceptions including pleasant and unpleasant experiences towards learning using the Narrative Approach. This study has crucial implications for Moral Education instructors and curriculum developer in creating a more effective and successful teaching approach of the courses especially for preservice teachers.
\end{abstract}

Keywords Preservice Teacher, Narrative Approach, Moral Education, Moral Reasoning

\section{Introduction}

Intelligence plus character (including moral reasoning) is the goal of real education (Martin Luther King, 1947). In addition, moral reasoning is central for teacher's education programme due to teachers' duty as moral models for students as they are predicted to behave ethically in the classroom (Chang, 2006). There are also several researchers that similarly stress teachers as moral models (Abebe \& Davis, 2006-2007; Cooper, 2004; Derryberry,
Snyder, Wilson, \& Barger, 2006). Hence, moral reasoning competence is indisputably to be one of the most crucial goals of teacher education programmes, which is not only important for preservice teachers in Moral Education teacher's programme but also for all preservice teachers as well.

Currently, the present study is an effort to explore preservice teachers' views and experience in learning in a Moral Education course (LHE3313 - Moral Issues and Conflicts) as a subject and it precisely examines these preservice teachers' perceptions towards learning a coursework in an alternative approach called as Narrative Approach. This study also wants to explore on how this Narrative Approach is capable in promoting preservice teachers' moral reasoning.

\subsection{What is Narrative Approach?}

Abbott (2008) differentiates narrative and story as; narrative, is the illustration of events whereas story is an event or sequence of events which also involves entities or characters. Consequently, Goodson (2010) asserts that Narrative Approach, is a facilitation of an educative journey through which learning takes place in thoughtful situation, and by engaging in meaning-making and deep dialogue and discussion. The goal of the Narrative Approach is to educate and explore through narrating, explaining and rebuilding the stories and experiences of instructors and students. In this study, the Narrative Approach was a method that taught preservice teachers by assimilating ideas through various Narrative Approach activities including drama, role-play, dialogues, storytelling, and so on to achieve educational goals such as to promote their moral reasoning skill. In other words, narrative approach is an approach to teaching and learning which is committed to the interpretation of teachers' and students' narratives about their experiences in education and live. 


\subsection{Why do this study?}

Presently, Moral Education teachers in Malaysian national schools tend to implement the ordinary teaching approach rather than the components of character education and cognitive moral development in their teaching (Chang, 2010). As an example of ordinary teaching approach in Moral Education, teachers believe that they should impose strict enforcement on students to memorise the set of values in the syllabus (Tho et al 2008). They perceive this is an important act in making sure the students obtain better results in Moral Education course in Sijil Pelajaran Malaysia (SPM). To be honest, however, this approach seems insufficient in promoting students' moral development. This is due to the fact that having a greater result does not guarantee a student to be a well-rounded morally educated person which acquires mature moral reasoning, moral feeling and moral action.

Furthermore, the received feedback from this ordinary instructional approach in teaching and learning of Moral Education subject in school has created a negative perception towards Moral Education programme in Malaysia, together with Moral Education teachers' education programme (Nur Surayyah, 2008). People tend to claim that Moral Education is an 'easy' and simple course which only requires students to memorize the values and keywords. Thus, this misinterpreted perception leads to another hazard sentiment, that is, the Moral Education teachers do not acquire enough training in their teacher education programme and that is the reason why they fail in promoting students' moral development holistically. Consequently, the aim to produce well-rounded morally educated students as Malaysian citizens will be demolished.

In order to adjust and improve the teaching and learning approaches of Moral Education, innovation in terms of teaching approach is needed in a teacher education programme. The Moral Education preservice teachers should be exposed to various teaching approaches to ensure that they have high creativity in teaching crucial course like Moral Education. One of the teaching approaches, which has been perceived as successful in facilitating preservice teachers' moral reasoning is Narrative Approach (Tappan, 1991). As Ironside (2013) mentioned, the key elements to ensure success in a teacher education programme was by making learning as a medium for inquiry and reasoning. In this sense, Narrative Approach with its nature of creating a space for critical thinking and self-reflection are perceived as useful in boosting the moral reasoning of preservice teachers.

Research by Mathew \& Lowe (2011) suggested that by implementing Narrative Approach in teachers' education programmes, it had allowed the preservice teachers to harmoniously integrate together their mind, emotion, and spirit, as well as values, worldviews, traditions, moral, and individual experiences. Therefore, it will create well-rounded Moral Education teachers, who are not only good in subject matter, but also capable in dealing with moral issues frequently occurring in Moral Education classroom. The Narrative Approach which is different from the existing approaches in the teaching of Moral Education could be worthwhile in directing students' attention to their moral experiences, therefore, they could promote them to have a better understanding of what is morally relevant and generate their moral reasoning skill as well (Dewey, 1934).

Apparently, there is a need to expose Moral Education preservice teachers with Narrative Approach to create a moral inquiry environment in their education programme. Moreover, the Narrative Approach will improve their moral reasoning skills by connecting the past, present, and future in the form of real moral experiences. In fact, all these criteria of Narrative Approach will help preservice teachers to make a better sense of their learning experiences (Tappan, 1989). Nevertheless, the use of Narrative Approach in a teacher education programme is a new phenomenon in Malaysia even though this method is quite prominent in other countries.

In line with the need to explore an innovative approach in Moral Education Programme in Malaysia, the focus of this study was to examine the learning experiences of Moral Education preservice teachers through Narrative Approach.

\section{Methodology}

\subsection{Interviews}

This study exploited a semi-structured interview. In this kind of interview, there were several general questions that will be outlined to be asked to the interviewees. The researcher showed openness to the interviewees' responses. However, the researcher probed for more detailed information based on the interviewees' responses. The interview method was used to get the stories from the students who have taken Moral Issues and Conflicts. The interviews were audio recorded using a digital audio recording device. Then, the audio recordings were transcribed. The interviews were conducted with the participants in a most comfortable and natural way. The interviews were held in the final week of the observation session.

\subsection{Observation}

Participant observation is an overall approach to inquiry and a data gathering method (Marshall \& Rossman, 2014). In this study, the researcher made her presence and purposes known to the Moral Education preservice teachers in the class. The researcher approached and clarified the reason of her presence to the students before the class began. The researcher also informed the students that she was going to select some of them to be interviewed as participants in this study. This had helped in developing 
rapport between the researcher and the students. The observation was held during the Moral Issues and Conflicts class for four times using techniques field-note taking. The purpose of using field-note taking techniques during observation was to acquire as much information as possible and complementing each data from other technique of data collection methods.

\section{Findings}

\subsection{The Experience of Moral education Preservice Teachers in Narrative Approach}

In order to explain the students' perceptions towards learning a Moral Education course using the narrative approach, it is crucial that their learning experiences are illustrated. It is imperative to note that these students had undergone many courses in their previous semesters with different teaching approaches being used in those courses. Thus, this section will explore the students' perceptions about their experience learning a Moral Education course using the Narrative Approach. Overall, it can be observed that the students perceived that learning Moral Education course using the narrative approach is different from using other approaches. The differences can be seen from the themes that appeared from the data resulting from the interviews as follows:

Table 1. Preservice teacher's experience of narrative approach

\begin{tabular}{|c|c|}
\hline Themes & Sub-themes \\
\hline Teaching approach & $\begin{array}{c}\text { Lesson through sharing experiences, ideas, } \\
\text { views } \\
\text { Student centered }\end{array}$ \\
\hline Instructor's role & Instructor's 'withitness' \\
\hline Class environment & $\begin{array}{c}\text { Interconnectedness } \\
\text { 'Safe' class environment }\end{array}$ \\
\hline
\end{tabular}

Table 2. Preservice teacher's experience of other approach

\begin{tabular}{|c|}
\hline Themes \\
\hline Lessons were teacher-centered \\
\hline Lack of sharing experiences, ideas, views \\
\hline
\end{tabular}

\subsubsection{Theme: Teaching Approach}

3.1.1.1. Lesson through sharing experiences, ideas, views

When the preservice teachers were relating their experience to learning other courses in their previous semester, the most apparent differences among all the students' experiences are the fact that in LHE 3313 they encountered a lot of sharing experiences, ideas, and views in the process of teaching and learning. While all of them started taking Moral Education courses since their third semester, they said that the Narrative Approach is something new and refreshing for them, with a lot of sharing and exchanged experiences, ideas, and views between students and lecturers. To verify, according to Ain, she realized that the Narrative Approach which was used in LHE 3313 is so different from other approaches that she had experienced, whereby in this course everybody must share their stories and their opinions as well [Ain/DU8]. Besides, Veen also restated, in this classroom, all students must present their moral issue's case study, therefore all of them must have prior knowledge such as stories or experiences regarding the topic to be shared during the case study's presentation [Veen/DU8]. Meanwhile, Azi related that the narrative approach is an approach that uses true stories or true experiences as the medium of instruction, in fact in discussing the moral issues, students must use their own stories or stories that they have heard from others in explaining their views or perspectives. In other words, they must recall their previous experiences regarding the moral topic and share them during the lesson [Azi/DU13].

\subsubsection{Student-centered}

A theme that clarifies the students' experience regarding the teaching approach was also extracted from the interviews and observations data. All the informants acknowledged that the lessons were very much student-centered in nature, through their instructor who combined numerous learning activities during the lessons.

From the researcher observation's session, she witnessed that there were lots of group work activities followed by oral presentations done by the students. In addition, students were required to do reflections regarding the topic by stating their stand regarding the issues by justifying their choices, and bringing up their self-experiences, and sharing it with the audience in explaining their decision/choice. Moreover, the class members were encouraged to listen carefully and give their full attention toward what was presented by their peers, at which point raised questions if any, and shared their thoughts as well. Consequently, this method is considered as a sort of a debate activity in the classroom. The students' statements clearly elucidate this point. Veen for instance, said:

"Like group presentation so the students they will directly confront the presenter, or they can add the points for example presenters tell out their points and they can agree or disagree with their point and they can voice out their experience. "[Veen/DU30]

On the same note, Shasha and Kim described the same experiences too:

"We tell each other stories about the experiences which could be related to the lesson of the day" [Shasha/DU24]

"Students are encouraged to give opinions and ideas and all, aaa.... The lecturer gives opportunity to students to share about the topic taught at that time". [Kim/DU28]

Students were not only given the tasks of finding information on their own and discerning the related ideas, they were also expected to discuss the ideas among 
themselves. According to Inda:

"In a lecture, this narrative is storytelling. How we aaa... think about some issues... and then, it is more towards discussion ... like that. That's what I understand." [Inda/DU48-50]

Besides, Kim stated that the lesson is more student-centered in nature as the instructor always facilitates students to be actively involved in class discussion by using probing questions. The instructor simply probed the students' questions, then the students would have to figure out their understandings and discussed it again with others accordingly:

"...it is different from this narrative approach, aaa, when we have any question, we just raise our hands, aaa, if the $\mathrm{Dr}$ allows us, she will say, give your opinion, then, everyone listens, ok what do you think about the opinion given? Do you agree or not? Why?"

\section{[Kim/DU64-66]}

In summary, the above shows the undeniable fact that the students perceived their experience in learning by using the narrative approach as different from their experience in learning by using other approaches.

\subsubsection{Theme: Instructor's Role}

\subsubsection{Instructor's 'withitness'}

All the informants agreed that, the most different part in narrative approach classroom is the instructor's role. This view was clearly specified through their responses during the interview sessions. Based on Veen's experiences, she said that, other than the course, one of the factors that made her be keen to come to LHE 3313 class was the instructor's role. She admitted that the way instructor conducted the lesson made her always look forwards to joining the next classes [Veen/DU12]. She mentioned that, the instructor played a crucial part in attracting student's attention, especially by showing her 'withitness' which means, that the instructor was constantly mindful of all that was going on in the classroom;

"First my lecturer will listen to the presentation as well after the presentation that she's really engages with it she really listens to that. Because later the points that she will tell ahh the small matter also sometimes as lecturers she realises. She is so concerned with what the students present and later when she tells out the point oo so for the next time we have to improve with this like that." [Veen/DU42]

This experience was similar to Inda's. As stated by Inda, she felt that the instructor conducted the lesson by always bearing in mind what was going on during the presentations and while the students share their stories. For her, it gives a sign that the instructor was willing to be open about herself and share her stories with the class members and the best part was, students gained a lot of understanding from instructor's self-disclosure as she has a broad life experience.
"There's a lot of sharing. Aaa... from the lecturer, when she shares we could relate it to our own experiences... ooo... like that... ooo... there's connection... aaa.. so when the lecturer shares her experience, she has a lot of experience. And then she gives me the chance to think... share experience... ooo... that's right... I can think too. My experience is actually related to that issue. Sometimes we are not able to relate the issue with our own experience but after we listen to her stories, we are able to relate them." [Inda/DU66-70]

The data from interview with the instructor also support the fact that instructor role's is the most crucial elements in implementing Narrative Approach. According to Dr A, based on her experiences of implementing narrative approach in Moral Education courses, the instructor must be engaged with the whole narrative of the students. She clarified that:

The lecture must be thoroughly involved, must be listening. Cannot be just talking and.. you know.. not listening. You must be listening to what the student is saying. And you must, they must be appreciative. Appreciate what the students are saying. Which means, we must react, respond, like the student say, i..i...i..you know I am this kind of person, so you must have the empathy, aaa..sympathy [Dr A/DU438-444]

Based on the students' and instructors' responses, it can be deducted that the instructor's role is considered as the most significant element in the narrative approach that seems to be different from other approaches. Clearly, all the informants agreed that the instructor's withitness engaged their attention to take part in the narrative approach classroom activities.

\subsubsection{Theme: Class environment}

\subsubsection{Interconnectedness}

All the informants clearly mentioned that the class environment in Narrative Approach classroom is consider as 'interconnectedness', which means, there is dual-communication element in the whole lesson. As mentioned by Ain, everyone must take part by sharing their views and ideas, which means that, not only the instructor must take the responsibility to prepare for the lesson, yet, students also should always be prepared with their knowledge toward next issues, so that they can together contribute their views and opinions in the class's discussion. According to Ain:

"Throughout my experience in the narrative approach, it is very good, everyone will take part in it. Then, we also know that the lecturer won't be the only person talking, everyone will speak, everyone will get ready..meaning that every student in the class knows what is the next topic that we will learn ah.. need to have information regarding the issue or the subject matter. If not the class will become quiet. So if we are aware of the topic we can share. We can express our opinions. The Dr will give her response and whether our view is correct or not, like that." [Ain/DU12] 
However, the interview with Kim disclosed that, for him, the interconnectedness element occurs in the form of the 'sense of belonging' between the class members of the Narrative Approach classroom itself. He stated that, the class setting which students are required to sit is next to other in a ' $U$ ' shape formation, give some sort of feeling that 'we are together'. He further elaborated:

“...aaa, an example that I see from Dr A's class is that, aaa, during the class in front of the surau, we were asked to move forward, closer to the lecturer, so we feel very close when we were in that situation." [Kim/DU98]

In fact, the researcher's observation data shows similar evidence with what that have been shared by the students and the instructor, which indicated there is an element of interconnectedness in the class environment which can be seen when each of the class members showed recognition of other people's points of view during the lesson. The students seem caring towards each other by the display of their togetherness when they set up the learning space as comfortable as they could. For instance, they arranged the chairs in ' $U$ ' shape to make sure everybody sat close to one another and could view the presentation clearly. Besides, from the observations, the researcher observed that all of them were always quiet and tried to minimize any disruption while their peers were presenting their cases or sharing their views and ideas.

\subsubsection{2. 'Safe' class environment}

Likewise, Kim shared the same facts with the researcher's observation data. As indicated by Kim, the Narrative Approach he experienced gave a 'safe' class environment in the sense that there was conducive class setting, together with engaging teaching approach that is different from other approaches, whereby this element attracts his attention very much.

"Aaa, the class environment... Okay, pers, honestly I love the class environment which is relaxed... Aaa, which is, like the class environment just now. Ehem, the arrangement was laidback, and, her teaching method, the Dr., so far, I actually like it." [Kim/DU70-74]

Apparently, based on the information shared by Kim, the instructor seems 'open' in giving students opportunity to voice out their ideas in the narrative approach classroom, as such, this element made the lesson become more interesting.

"..I like her teaching method, I like the kind of lecturer who, as people say, is laidback, open, and gives chance and space to students to express their views, that's why it's good. " [Kim/DU78]

Like Kim, Inda admitted that the 'safe' environment for her is, a satisfaction feeling in giving views or justification in a discussion without being judged by her other friends. Besides, everybody got the same chance to elaborate their perspectives so that they could realize their thought and share it with their friends [Inda/DU98]. She further elaborated:

"...for the narrative method, the other day we...aaa.. had discussion in class. After that the Dr. asked, okay... do you agree, you agree, you agree...I think this thing gives me satisfaction to students to aaa... give their opinions two-way... meaning, okay... someone does not agree, okay... he said he doesn't agree, why doesn't he agree? So that person will explain and the Dr. aaa... replies.. gives response... oh, okay, why do you disagree, making assumption, assumptions like this. Is there any other person making assumptions? So, that is when the students have the chance to share how they think. And aaa... at the same time, aa... we have the opportunity to share aaa... our opinions... haa... like that".

Eventually, what has been stressed by preservice teacher is congruent by what has been elucidated by the lecturer in the interview session. Based on the interview with Dr A, she explained that to ensure the successful implementation of the Narrative Approach in one course, the 'openness' element in the classroom environment is considered as a vital part. Everyone should have a sense of 'genuineness', which means, they are sincere to listen, play non-judgemental roles, and respect each other as well. She elaborated that:

"There must be a space..a safe..space..safe meaning open. Genuine.. I think genuine is very important where everybody was just listening not criticizing. There was one in certain way where a student criticized and that created urmmm..everybody felt aaaaa..their gut when up.. like they don't want to say many things because somebody was sayingwhat they were saying was..is wrong..It must be safe for them, and everybody must be made aware of it. All the participants in the narrative... They should res..there must be a mutual respect..And mutual understanding that what is been said is within the context of their learning.. [Dr A/DU208-214]

Dr A further clarified that learning with the Narrative Approach as their teaching approach will only be taking place if both the lecturer and students are able to create the openness, the 'safe' space to share their views and perspectives in class activities:

"So that..that safe the environment, opens space must be there..there..must be.. and that requires the facilitator or the instructor or the lecturer must also be open... Open to the ideas..hurmm..Any moment the..the..the instructor or the lecturer step in.. owhhhh..that is wrong. That will stop the narrative. Once you stop the narrative, you stop the learning. The learning will not be taking place" [Dr A/DU218-222]

Obviously, from the interviews, students specified that they love learning environment that provided opportunities to discuss in two-ways communication, in 'lively' environment whereby all the class members have the chance to be heard equally with mutual respect. 


\subsubsection{Theme: Lessons were teacher-centred}

Most of the informants revealed that the method of teaching used by their instructors in other classes is different from the Narrative Approach. From the interviews it can be noted that they commented on the other classes for being mostly teacher-centred with a lot of lecture sessions. According to Shasha:

"Because in other classes we only have lectures, we only listen... listen...listen.. listen and the lecturer tells us everything. And sometimes we don't even bother. After this aaa... we only want to sit for the final exam." [Shashal DU46]

Kim indicated the same thing by claiming that there is a huge gap between the narrative and other approaches he encountered. According to him, other course works seem to be more teacher-centred in nature, and all the time instructor will be in charge of the lesson.

"Different from the approach which, emm, what people call, educational approach... traditional lesson, people say... because the teacher talks at the front, teaching... writing at the front or explaining notes. At the same time, the students, the pupils, aaa, sit and pay attention... They only ask questions if the teacher allows them..." [Kim/DU58-64]

This is reconfirmed by Azi by claiming that, the other coursework he attended was teacher-centered in nature with more focus on the content, even though they did have lot of presentation:

"Hmmmmm ... if aaa ... the other approaches... they are focused on ... hmm... facts.. the lesson itself. Or the subject itself. The content itself. Where... in the usual approach used in other typical subjects they are more towards presentation. Presentation on the content ... okay. When it is finished, we get marks. The lecturer gives the marks." [Azi/UD31-33]

Clearly, most of other coursework lessons that the preservice teachers attended, used to be a 'one-way communication' with the instructor taking control of the class most of the time.

\subsubsection{Theme: Lack of sharing experiences, ideas, views}

From the interviews, a couple of informants stated that, in terms of opportunity to share experiences, ideas or views, they prefer the Narrative Approach. According to Shasha, the other approaches she encountered seem lacking in the element of experience sharing. Even though there were group presentations, most of the students conducted it with the intention to compete with one another and to be the best group in presenting their task. Consequently, this notion will lead them to ignore other classmates' views and beliefs. As Shasha mentioned:

"Because, even though it is narrative (approach) we can listen to other people's views. In group (work), we compete... it's cooperative learning, most people compete on whose idea is better and we don't care. We only want to criticise others. In narrative (approach) there's no wrong, no right. It's about experience. When we use it, there is no sense of competition so much." [Shasha/DU96-98].

On the same note, Inda too described the same experience when she said:

"Okay...aaa.. actually the narrative approach is only in moral classes... if we look at the other subjects... they are more towards presentation...And in presentations, we only share what we have... like our research findings on certain matter... umm, okay, in presentation ... emm ... we do field research, do assignments, there's no sharing of experience..." [Inda/DU94-98]

According to Inda, in other approach there are group work and presentations, but it seems still lacking in the sharing of experiences, ideas, views. But in the Narrative Approach class, there were lots of discussion between class members (two-way communication) and that can make students feel content with the lessons. She added that:

"But for this narrative (approach), that day we... aaa... discussed in the class. After that the Dr. asked, okay... do you agree or not, you agree, you agree... I think this approach gives students more satisfaction to, aaa... gives their opinions in two-way..." [Inda/DU98].

Briefly, from the above students' statements, the preservice teachers perceived their experience in learning using the Narrative Approach as different from their experience using other approaches in terms of sharing experiences, ideas and views.

\subsection{Preservice Teacher's General Perceptions about Narrative Approach}

To discover the students' general views about Narrative Approach, the researcher raised up the following question: "What is Narrative Approach to you? What are your views about Narrative Approach?" The data from the interviewees' responses revealed three main compatible themes:

Table 3. Perceptions towards narrative approach

\begin{tabular}{|c|}
\hline Themes \\
\hline Promote student understanding \\
\hline Create student empowerment \\
\hline Difficult but worth it \\
\hline
\end{tabular}

\subsubsection{Theme: Promote student's understanding}

The students perceived the Narrative Approach as an important aspect of learning in their development as students and as future Moral Education teachers. Quoting Veen who stated, "Urmm.. effectiveness why, I feel it's good actually because urmm if we compare it to other lecture because of the heaviness of the subject, also we can tell, it is actually suitable for moral subject to have the narrative approach. Because students can explain what they 
know and voice out their points. This makes them understand in deep about that particular topic. The issues, the moral issues." [Veen/UD10], and Azi who mentioned "So, if other people's experience, which we have never gone through, we can add it up... hmm... for us to tell later or so that we can understand more deeply about the issue" [Azi/DU19]. She also mentioned that "So, for our friends whose lives are... hmmm, quite difficult, their experience is more... more than us. Their experience is different than us. So this helps me a lot in... emm... becoming a teacher aaa... a Moral Studies teacher because our students or our target (audience) are different. So through this experience, it helps me to understand people better, how they are and how they are different. [Azi/UD25].

Their opinions clearly show the significant impact of the Narrative Approach to their deep understanding on moral issues. Veen elucidated that the Narrative Approach is effective in facilitating students' understanding, as for her, moral courses are not an easy coursework to be understood, therefore the opportunity to express their views will make students think deeply about the topic. In other words, it gives her better insight in understanding the course content. As for Azi, she felt that sharing experiences in the Narrative Approach makes her have more understanding about moral issues. She feels that, it will improve her knowledge as a university student. Moreover, she stressed that being competent in understanding moral issues would help her in the future as Moral Education teacher as she acknowledges the differences of students.

The same is true for Inda, who admitted that the Narrative Approach is crucial in her future as a teacher in understanding the variety of moral stands of other people "after this when we become teachers, we are future teachers, when we are teachers we have to understand that every person has their own individual moral standing" [Inda/DU86]. Clearly, Inda's perception is equivalent to Veen's and Azi's views towards the Narrative Approach. There are two points here. First, the students believe that the Narrative Approach as crucial in their lives because it can open up their understanding toward moral issues. Another one is, as indicated by Azi and Inda, the Narrative Approach gives a lot of possibilities for them to build up the character of Moral Education teacher in the future. Accordingly, these data supported the comments by Dr A who indicated that, there's no doubt that the Narrative Approach means a great deal to the students in understanding what is moral and what is to be a moral person and hence behaving morally [Dr A/DU74-80].

\subsubsection{Theme: Create student's empowerment}

A definition of "empowerment" as "bringing into a state of belief one's ability to act effectively," is offered and the critical importance of effective relationships between teachers and students is stressed. Principles of mutual respect, validation, and focus on success are seen as empowering for both students and teachers. Another theme that emerged from the interview with one of the students is that the Narrative Approach is perceived as an approach that fosters student's empowerment in terms of student's participation [Kim/DU56]. Actually, his view is parallel with the view of the instuctor's interviewed. The instructor stated that "Aaaa...narrative brings their voice... The voice here is referred as to their views, their perspective, their situation which is not individual" [Dr A/ DU90].

The perception that the Narrative Approach can develop student's empowerment is also emphasised by Shasha who declared "Everyone has to take part. Yes... must contribute something and give response..." [Shasha/UD99-100]

\subsubsection{Theme: Difficult but worth it}

From the interview's session, most of the informants perceived that the Narrative Approach is an approach that is quite difficult to be mastered, but worth mastering according to Veen, as she could understand the course content very well from the narrative approach:

"Emmm I can understand subject very well. which means it is not just like the other subject. Emm it is not easy actually to understand, not but the way like we get more knowledge it is not that we have to what like everyone have to errmm study this back like for other not necessary to study what is coming up based on the lecture notes only" [Veen/DU26]

The perception that the Narrative Approach is difficult is also highlighted by Azi, who mentioned that the lesson will only be much easier if students make early preparation prior to the lesson:

"Aaaaa.. my initial expectation was like... these moral issues, the lecturer will bring them... meaning the issues will come from her. The normal issues. Typical... that are easy to be understood. But I didn't expect the lecturer would ask us to find the issues ourselves, to relate it to the topic given to us and... to understand what the issue we bring forward is. So it's like... aaa.. we need to search for cases and all... Mmm... if we prepare earlier, it will be easier." [Azi/DU153-155]

It is evident from the data analysis regarding students' perceptions towards this approach that the Narrative Approach is an important aspect of learning for them as students and future Moral Education teachers, but at the same time they acknowledged that the approach is quite difficult, but then worth mastering.

\subsection{The Benefit of Narrative Approach}

Regarding the researcher's attempt to examine the benefits of the Narrative Approach for the preservice teachers, the data analysis showed two main findings. It was discovered that the benefits of Narrative Approach on students' development are in terms of moral reasoning and soft skills. 
Table 4. Perception on benefits of Narrative Approach

\begin{tabular}{|c|c|}
\hline Themes & Sub-themes \\
\hline Moral Reasoning & Reflection \\
\hline Soft Skill & $\begin{array}{c}\text { Self-confidence } \\
\text { Empathy }\end{array}$ \\
\hline
\end{tabular}

\subsubsection{Theme: Moral Reasoning}

\subsubsection{Reflection}

From the interviews, the benefits of Narrative Approach according the preservice teachers, were in terms of reflection practice that occurred while using the approach. That perspective was voiced out by Veen who clarified:

"...for me it really gives me a lot of benefits, we will use the approach in class and do reflection. So, the reflection also will help us more to explore more. Not only with the voice that we have in our class because the session is limited 1 to 2 hours like that, so it is not enough for us to get all the knowledge and when we are having reflection session, we explore more when we search article regarding that particular topic. Ermm we get to know more regarding particular topic" [Veen/DU14]

Veen elucidated that in order to complete the reflection task, she needed to explore a lot of information regarding the moral issues, hence that practice exposed her to various facts in relations to the moral issues. In other words, the reflection task enriched student's moral knowledge and understanding. Besides, Veen admitted that such reflection leads her to use her reasoning skills. "So, when I explore, I can get more knowledge and facts supporting and them opposing this. So, I can what... do reasoning" [Veen/DU14].

Sharing the same views with Veen, is Ain who indicated that, she made reflection by relating her friends' experiences with her own as sometimes they are different from hers. According Ain:

"For all these moral issues, not all of them we have been through so by using the narrative approach we can listen to other people's experiences so that we can apply their experience in our life, we can also share with other people." [Ain/DU94].

It can therefore be claimed that, the reflection practice in the Narrative Approach benefits students in applying their reasoning skills in issues related to morality.

\subsubsection{Theme: Soft skills}

\subsubsection{Self-confidence}

Another benefit of the Narrative Approach according to the preservice teachers was in terms of soft skills. As mentioned by Ain, the Narrative Approach increased her confidence as well as the sense of responsibility as it requires students to take part in class discussions for each class. Ain said:

"Umm, the skill like I said, I am not an outspoken person, but when we are doing the narrative (approach) we feel more confident, we feel more responsible because we know that every week there is something that we have to convey." [Ain/DU63]

The finding also indicates that overall, Kim too gained benefit from the Narrative Approach in terms of his confidence level, "Aaa.. the skills, that is, like... like I said just now, what ... brave, brave... like people say, brave to express opinions. [Kim/DU264].

It is therefore evident from the interviewees' statements that students gained benefit through the Narrative Approach in terms of increased confidence level in expressing their opinions and sharing their experiences that are related to the moral issues being discussed.

\subsubsection{Empathy}

Another benefit of Narrative Approach is it encourages empathy. According to Azi, other than helping her so much in terms of understanding moral issues, it also often triggers the feeling of empathy towards other friends' experiences or stories. She explained:

"Aaaa ... it can benefit in terms of... aaa ... as I said just now... experience ... and in the experience that we share we can get like... aaa... internalize... how do I say... we get into that other person's experience." [Azi/DU25].

She added that, as she is a future Moral Education teacher who will teach students from various backgrounds, therefore the sense of empathy is crucial for her to understand them better. She added:

"So this helps me a lot in... emm... becoming a teacher aaa... a Moral Studies teacher because our students or our target (audience) are different. So through this experience, it helps me to understand people better, what they are and how they are different" [Azi/DU25].

Clearly, students' perspectives revealed that the narrative approach gives much benefit for them in cultivating empathy as a preparation for them to be better Moral Education teachers.

\subsection{The Preservice Teachers' Feeling About Narrative Approach}

Based on the analysis of the data on the preservice teachers' feelings about Narrative Approach, the researcher discovered that they expressed mixed feelings. There are two key ideas that the students emphasised regarding these feelings.

\subsubsection{Theme: Pleasant feeling}

Initially, most of the informants revealed that they felt good about learning in the Narrative Approach class. The data disclosed that the students did feel that their Narrative Approach class was enjoyable and helpful. As mentioned by Ain, she could relate the pleasant feeling with the sense of confidence to voice out her ideas because there are no right or wrong answers. According to her: 
"To me it is interesting because everyone likes to talk when we use the narrative approach, everyone can get involved. Not just the same people talking. Sometimes there's someone who wants to speak but he's afraid to speak, so when we use (the approach) sometimes I feel more confident. There's no right or wrong. " [Ain/DU48]

On the same note, Shasha admitted that, she did enjoy the Narrative Approach class as this approach changed the way she learned, which is from individual type to easy going person in terms of group work "Mmm... I like it and I'm satisfied with it. I mean it changes the way I learn a lot" [Shasha/DU114]. The same goes for Inda who said that she really enjoyed the Narrative Approach class as it brings a lot of positive effects in her life, such as satisfaction because she was able to express her feelings and ideas [Inda/DU118-112].

Besides, Kim too confirmed that his experience in the Narrative Approach was great. Kim confessed that at the beginning, the LHE3313 course with Narrative Approach a challenge to him, but he discovered in the end that it wasn't difficult anymore as he really enjoyed the class activities. In his experience of the Narrative Approach, there were discussion and sharing of views, he found those activities assisted him in improving his confidence to voice out ideas in front of others. He elaborated that at the beginning he felt anxious when the instructor seemed to be forcing him to give his thought about an issue. But then, he tried his best to give a try and finally discovered that practice trained him to be prepared and to never give up no matter what. Eventually, he was so comfortable and really enjoyed in the Narrative Approach class:

"At first, I felt a little awkward, it was hard... Because I'm that kind of... before, I thought that the lecturer was just forcing us to give our opinions, so I was not used to it. It was like, I wasn't ready at that time. Before this I was like that, but now, I have to, like it or not, I have to tell myself, ready or not ready, if the lecturer says to me, "ok Kim, give us your opinion"...I would say, oh no, but it's okay, I will give it a try. Like that. I was shy indeed but I had to set that feeling aside and I tried. Now... Now I'm more comfortable ... enjoying it." [Kim/DU466-480]

Clearly Ain, Shasha, Inda and Kim were very happy with the Narrative Approach in LHE3313 as the way the lessons were conducted to help them in building up their characters in terms of confidence to express views and ideas, and as a person on how to be flexible. Accordingly, these data were supported by Dr A, as she mentioned that narrative attracts students' focus and it creates joy in lesson. She said that "Because they were focused. They focus on and they...they are very en...they were very enthusiastic, they were very happy" [Dr A/DU176].

\subsubsection{Theme: Unpleasant feeling}

Even though the students had good feeling about Narrative Approach, they also admitted that sometimes, they felt unpleasant in Narrative Approach class. As explained by Ain, an example of unpleasant feelings regarding Narrative Approach is when she had to deal with anger because of ideas' rejection:

"For example, we have our own stand on something but then someone said something opposite, which makes you feel angry." [Ain/DU106].

Additionally, Ain claimed that the angry feeling was associated with low self-esteem feeling as well:

"Sometimes we would feel offended when we say something, people just refute us. It feels like... was I so wrong to say what I said because when someone would speak out against us we feel, frustrated with other people's view, opposing us... because we will still say the same thing to stand our ground." [Ain/DU114-118]

However, from what Ain said, she tries to take it as something positive, in addition to trying to be rational by believing that individuals are diverse, and she should appreciate the differences. Eventually, by thinking that way, she could build 'enjoyable' feeling rather than 'angry' feeling in the narrative approach, as it is part of debate activities in the lessons. According to her:

"It doesn't actually make me feel down but it makes me more rational, meaning that I'm able to think, oh, other people have different views from mine, I'm not the only one who is right. I don't feel upset straight away. It doesn't feel too bad... It's like, I'm ready because I know that everyone is different, as I said, we celebrate the difference. It's nice to hear other people with their different views. This makes us think and be more rational about certain issues." [Ain/DU122-126]

It seems that not only Ain was feeling unpleasant in the Narrative Approach class, but also Veen found that the lessons sometimes did trigger her ego as she mentioned that she had high 'ego' and was easy to get angry. She described that before this, it was not easy for her to face rejection of her opinions, but after she had been through several sessions of Narrative Approach, that feeling changed. She realized that people will only get offended if they do not understand why others deny their views and opinions, but in this Narrative Approach case, she can clearly understand about the moral issue's discussion then the debate element in the class's activity. According to Veen:

"Ok we should not get offended when people deny our points so people like they aaarrr yes, I have this bad habit like getting angry. My interest has changed a lot like here I am getting back to the normal. And yes, I have high ego. Yeaa and this ego I realise when I enter this university before that I just can't accept anything but maybe some personal experiences (narrative approach) make me change. Yeah like for me because I understand so I don't get offended. If I didn't understand one fact, then I might get offended. But here I can understand..." [Veen/DU70-74] 
In addition, Kim also indicated his unpleasant feeling in Narrative Approach during the interview. Kim's response clearly reflects this:

“...not with a surprise. Eh, she didn't ask for it but suddenly she gives questions on the spot, I wasn't ready, like that..." [Kim/DU490-492]

Apparently, Kim responded that way because he stated that he did not know why suddenly the instructor asked him a lot of questions during the class discussion. In addition, he felt that he was not ready at all to answer the questions in front of others. He also said that the instructor should inform the students earlier regarding new technique that she wanted to implement in the class [Kim/DU484]. However, he did mention that sometimes, it is not the instructor's fault as suddenly he realized that $\mathrm{Dr}$ A did explain all about the Narrative Approach that she intended to implement in that class in the beginning of semester, but he was the one who was not aware of it [Kim/DU496-500]. Due to his failure to pay full attention during the first class of LHE3313, he felt demotivated [Kim/DU502]. Kim also stressed that there was certain topic (moral issues) that for him was not so interesting. He additionally claimed that, it made him so bored and, at that time, he just wanted to sit in the class and did not want to be involved in the discussion [Kim/DU514].

\section{Discussion}

\section{What are the Moral Education preservice teachers' perception of Narrative Approach as they experience it?}

The discussion will scrutinize the findings in term of the connected literature and theories. Based on the discussion of the findings in the prior section, the researcher would like to present that in this research, the perceptions of the preservice teachers towards Narrative Approach were formed by their experience in learning both the narrative and other approaches, as well as their general perspectives toward the Narrative Approach, together with their views regarding the benefits of the Narrative Approach in their moral development and their feelings toward their experience in the Narrative Approach as well.

Regarding their experiences, it can be summed up that from the existing proofs, indisputably the students perceived their experience in learning moral courses with Narrative Approach as different from their experience in learning with other approaches in certain ways.

First, in the Narrative Approach, it emphasizes learning through shared experiences, ideas, and views within the class members. Whereby in other approaches, there is lack of sharing of experiences, ideas, and views in the lesson. Second, the preservice teachers perceived that Narrative Approach lessons were more student-centered, meanwhile in other approaches, lessons seem to be more to teacher-centered in nature. It means that, in other approaches, students rely so much on their instructor in contrast with the Narrative Approach where students are the active participants in the learning process. Indeed, there is no denying that the Narrative Approach emphasises on student centered ability (Bruner, 1986) and is far more capable in enriching people's understanding compared to other approaches.

Next, in terms of the instructor's role, the preservice teachers perceived that learning with the Narrative Approach often associated with the element of instructor's 'whititness' compared to other approaches that do not necessarily show this criterion. Kounin (1970) asserted that 'withitness' relates significantly with students' participation and autonomy. In fact, Brophy and Evertson's (1976) study of teacher effectiveness is considered as one of the most important research findings that strongly support Kounin's findings regarding the 'withitness' factor of an instructor.

Subsequently, the researcher notices that there is a gap between the class environment in the Narrative Approach classroom compared to the class environment of other approaches. The findings showed that in narrative classroom, the classes are found as 'interconnected' whereas it is the opposite in other approaches. As mentioned by the informants, 'interconnected' means there is dual-communication component in the whole lesson in a Narrative Approach classroom. Also, there was evidence of 'safe' class environment element in a Narrative Approach classroom according to the preservice teachers. These findings are parallel with the constructivism theory by Vygotsky (1977) which proposes that cognitive development is subjected to the quality of interactions between individuals and the class environment. Therefore, the researcher agrees with Hensley-Pipkin (2015) that classroom environment has massive role in learners' beliefs and practices in the teaching and learning process. In this study, it has been proven that there exists strong connection between the preservice teachers and their instructors, together with the learning environment as well. Furthermore, previous researches suggest that, a well-planned learning environment that is rich with active, social learning experiences affiliated with human knowledge acquisition holds the potential to increase the chances of engagement and achievement of the learners (Kendall, 2011; Krapp, 2005).

In addition, in terms of general perceptions of the preservice teachers regarding their experiences in the Narrative Approach, this research found that the Narrative Approach helps in enhancing preservice teachers' understanding, together with developing learners' empowerment by way of learners' participation. Fortunately, this finding was congruent with the study by Mohd Yusof et al. (2011) that indicated effective learning process (including learner's understanding) happening when both instructors and students interact and actively 
participate in the learning activities. Furthermore, the finding also matches with the Inquiry Based Learning model by John Dewey (1934) that emphasizes learners' participation in discussions or engagement in meaningful reflection to generate their understanding (Dewey, 1934). The data analysis regarding the preservice teachers' general perceptions towards the Narrative Approach discloses that some students admitted that the Narrative Approach is a new approach which was tough for them to adapt with, nevertheless they acknowledged that this approach is worth to be learned as it brings a lot of benefits for their future as Moral Education teachers.

Next, in discussing the preservice teachers' perspective regarding the benefits of the Narrative Approach, this study found that the benefit of the Narrative Approach to the students was in terms of promoting moral reasoning capability through reflection practice in LHE 3313 lesson. This finding is compatible with the Inquiry Based Learning Model by Dewey (1934) which asserted on the element of reflection in the learning model. Dewey (1934) stated that the reflective practice is very useful in promoting learners' moral reasoning skill. Consequently, this study's finding is compatible with the research by Sholikhah, Susani, Prabandari, and Rahayu (2018) that indicated that learners' reflective ability was positively interrelated with their moral reasoning capability. On the other hand, the findings also indicated that the Narrative Approach is proven beneficial in cultivating the preservice teachers' soft skills such as self-confidence and empathy. This seems a new finding, as from the review of literature done by the researcher, there is no previous research specifically indicating such finding before this.

Other than that, the researcher also explored the preservice teachers' feelings about their experiences of the Narrative Approach. The findings revealed that there are two feelings that were experienced by the preservice teachers', which are pleasant and unpleasant feelings. Regarding the pleasant feeling, three of the informants related it with the sense of confidence to voice out their ideas because there are no right or wrong answers, therefore they felt free to express their opinions without being judged by the class members. But then again, another two of the preservice teachers elucidated that the pleasant feeling was related to the satisfactory feeling since they could express their thoughts and ideas in the class activities or in other words, they felt content in the Narrative Approach classroom.

Nevertheless, in terms of unpleasant feeling, Ain and Veen explained that their unpleasant feeling was as a result of feeling rejected when their opinions were opposed by other colleagues, though, they admitted that the feeling was just temporary, and they managed to control it by realising that it is just a part of socialization process. Eventually, according Kim, his unpleasant feeling was due to the lack of preparation for the topics to be discussed on that day, but he realized that was due to his own mistake for being ignorant when the instructor gave the tasks' instructions in the previous class. Accordingly, this finding is compatible with the constructivist learning theory, which asserted that human beings learn more when they are actively engaged in the learning process as they build knowledge through investigation and their own discovery (Piaget, 1954). which means that, the class activities guide the preservice teachers to experience the learning process by filling their needs and interests together with encouraging social interaction. In other words, learning activities is purposely to inspire students' interests (feeling) and motivate their problem-solving skill (Rushton \& Larkin, 2001).

\section{Conclusions}

The preservice teachers had a completely different learning experience before they experience the Narrative Approach and while they are experiencing other approaches during their studies in UPM. There were two prominent features of how they perceived learning in approaches other than the Narrative Approach, first, lessons were teacher-centered, second, the lack sharing experiences, ideas and views. In contrast, the preservice teachers were exposed to a wholly new experience when they experienced the Narrative Approach. The teaching approach was different, whereby lessons through shared experiences, ideas, views became the main method of instruction and unexpectedly the preservice teachers appreciated that teaching and learning process as it was more student-centered. In terms of the instructor's role, it was also different - as they could sense the instructor's 'withitness' as the class took its course.

There was also a shift in the class environment whereby it had a 'safe' feeling and interconnectedness in the learning atmosphere. These differences actually shaped the students' views towards learning in the Narrative Approach classroom. Additionally, the preservice teachers' views learning in the Narrative Approach as beneficial in their lives as students and for their future career as Moral Education teachers. They strongly believe that the Narrative Approach experiences could promote their understanding deeply toward moral issues or even understand the variety of their future students' background. Moreover, the preservice teachers perceived that the Narrative Approach they experienced gave them a sense of empowerment in terms of active participation in class activities. Last but not least, their general perception towards Narrative Approach is one approach that seems difficult to explore, to master, however it has its own strength and worth to be learnt according to the preservice teachers. However, they admitted that to be well prepared in the Narrative Approach, they must make an early preparation before the classes.

Next, in terms of the benefits of Narrative Approach on the preservice teachers' development, this study found two 
main elements; moral reasoning and soft skills. In terms of moral reasoning, the benefits could be seen through the reflection practice that let the preservice teachers explore various resources regarding particular moral topics. This will enrich student's knowledge and understanding towards moral content specifically. As a result, that will give great benefits towards students' moral reasoning capability as well. Secondly, in terms of soft skills. This study found that, exposure to the Narrative Approach promoted students' confidence level as well as responsibility to take part in classes activities, to share their knowledge, experiences and views regarding moral issues being discussed. Another soft skill that was enhanced from the exposure of Narrative Approach is the empathy skill. According to the preservice teachers, the sense of empathy is crucial especially for a future teacher, in order to sense and understand the students' needs especially when they come from various socio- economic backgrounds. Therefore, they feel that by being exposed to the Narrative Approach, it could train their feeling of empathy from the sharing of experiences activities during the case study presentation.

However, this study found that the preservice teachers' feeling towards this Narrative Approach experiences can be considered as mixed. They admitted that they felt enjoyable and pleasant during this Narrative Approach classes, however they felt unpleasant too. In terms of pleasant feeling, they elucidated that they enjoyed it because they could freely express their opinions without being judged by others. Therefore, they felt confident to express their voices, and felt satisfied in that classes. Another theme that arose in the interviews is, one preservice teacher admitted that at the beginning he felt unpleasant when the instructor seemed as if she was forcing all the students to give their opinions, but then, he found that, this approach gave so much benefit to him, especially in terms of improving his self-confidence level, therefore he really enjoyed this Narrative Approach class. Though they were enjoying the Narrative Approach so much, however they admitted that they also experienced some unpleasant feelings during the Narrative Approach classes.

According the preservice teachers, they felt uncomfortable when facing ideas rejection during the class discussion. This is because, in the Narrative Approach classes the, the learning process is more towards discussions and debate over moral issues, therefore everybody has their right to agree or disagree with other people's opinions. One of the preservice teachers also mentioned that her unpleasant feeling in Narrative Approach was in terms of her 'ego' which was challenged while her ideas were opposed by her other friends. Kim also elucidated that sometimes the unpleasant feeling arose while he felt that the instructor suddenly asked him a lot of questions during the lesson. As he perceived himself as an introvert person, he felt uncomfortable at first and felt that this approach seemed so abrupt and he was not well prepared for that. However, then he realised that the instructor had already explained about this Narrative Approach in the earlier class, but he was not initially aware about the new approach that the instructor would use in the LHE 3313 class.

\section{REFERENCES}

[1] Abebe, S., \& Davis, W. (2006-2007). Transcendence in the public schools: The teacher as moral model. Retrieved February 20, 2018, from http://www.collegevalues.org/arti cles.cfm.

[2] Abbott, H. P. (2008). Narrative and emergent behavior. Poetics Today, 29(2), 227-244.

[3] Anderson, L. M., Stevens, D. D., Prawat, R. S., \& Nickerson, J. (1988). Classroom task environments and students' task-related beliefs. The Elementary School Journal, 88(3), 281-295.

[4] Bennett, M. J. (2017). Developmental model of intercultural sensitivity. The International Encyclopedia of Intercultural Communication, 1-10.

[5] Brophy, J. E., \& Evertson, C M. (1976). Learning from teaching: A developmental perspective. Boston: Allyn \& Bacon.

[6] Chang, L. H. (2006). Teachers as agents of values: Malaysian perspective. Jurnal Pendidikan, 26, 51-60.

[7] Chang, L. H. (2010). An appraisal on the implementation of moral education for schools in Malaysia. In Procceedings of the 4th International Conference on Teacher Education; Join Conference UPI \& UPSI.

[8] Cooper, B. (2004). Empathy, interaction and caring: Teachers' roles in a constrained environment. Pastoral Care in Education, 22(3), 12-21.

[9] Derryberry, W. P., Snyder, H., Wilson, T., \& Barger, B. (2006). Moral judgment differences in education and liberal arts majors: Cause for concern? Journal of College and Character, 12(4), 2-10

[10] Dewey, J. (1934). Having an experience. Art as experience, 36-59.

[11] Elkind, D. (1967). Egocentrism in adolescence. Journal of Child development, 1025-1034.

[12] Goodson, I. F., Biesta, G., Tedder, M., \& Adair, N. (2010). Narrative learning. Routledge.

[13] Hensley-Pipkin, C. G. (2015). Use of the Physical Classroom Environment as a teaching and learning tool including the impact of the CCSSI in kindergarten through third grade classrooms in Northeast Tennessee (Doctoral dissertation, The East Tennessee State University, Tennessee, United States).

[14] Ironside, P. M. (2013). Narrative pedagogy: Gathering our collective wisdom to transform nursing education. In International Narrative Pedagogy Conference, Farmingdale, NY, USA (pp. 5-7). 
[15] Kendall, P. C. (2011). Child and adolescent therapy: Cognitive-behavioral procedures. New York: Guilford Press.

[16] Kounin, J. S. (1970). Discipline and group management in classrooms. Oxford, England: Holt, Rinehart \& Winston.

[17] Krapp, A. (2005). Basic needs and the development of interest and intrinsic motivational orientations. Journal of Learning and instruction, 15(5), 381-395.

[18] Marshall, C., \& Rossman, G. B. (2014). Designing qualitative research. California: Sage publications.

[19] Mathews, S. R., \& Lowe, K. (2011). Classroom environments that foster a disposition for critical thinking. Learning Environments Research, 14(1), 59-73.

[20] Mohd Yusof, K., Helmi, S., Jamaludin, M. Z., \& Harun, N. F. (2011). Cooperative problem-based learning (CPBL): A practical PBL model for a typical course. International Journal of Emerging Technologies in Learning, 6(3), 12-20.

[21] Nur Surayyah Madhubala Abdullah (2008). Reframing the notion of others in moral and citizenship education for a plural society. In Chang Lee Hoon, Norani Mohd Salleh, Wan Hasmah Wan Mamat \& Vishalatche Balakrishnan (Eds) (2008). Asia pacific moral, civic and citizenship education: new vision \& new realities. Kuala Lumpur: University of Malaya Press. Pp. 31-40.

[22] Piaget, J. (1954). The construction of reality in the child. New York: Basic Books.

[23] Rushton, S., \& Larkin, E. (2001). Shaping the learning environment: Connecting developmentally appropriate practices to brain research. Early Childhood Education Journal, 29(1), 25-33.

[24] Sholikhah, E. N., Susani, Y. P., Prabandari, Y. S., \& Rahayu, G. R. (2018). Is there a relationship between personal reflection ability and moral reasoning ability in Indonesian medical students? International Journal of Medical Education, 9, 213-218.

[25] Tappan, M., \& Brown, L. M. (1989). Stories told and lessons learned: Toward a narrative approach to moral development and moral education. Journal of Harvard Educational Review, 59(2), 182-206.

[26] Tappan, M. B. (1991). Narrative, language and moral experience. Journal of Moral Education, 20(3), 243-256.

[27] Tho, L. Y., Hoon, C. L., Salleh, N. M., Hasmah, W., Mamat, W., \& Balakrishnan, V. (2008). Reflections on changing the mindset of a moral education teacher. AsiaPacific Moral, Civic and Citizenship Education, 103.

[28] Turner, J. C., Thorpe, P. K., \& Meyer, D. K. (1998). Students' reports of motivation and negative affect: A theoretical and empirical analysis. Journal of educational Psychology, 90(4), 758.

[29] Vygotsky, L. S. (1977). The development of higher psychological functions. Journal of Soviet Psychology, 15(3), 60-73.

[30] Zizek, B., Garz, D., \& Nowak, E. (Eds.). (2015). Kohlberg revisited. Springer. 